\title{
Genetic variation in the Cytb gene of human cerebral Taenia solium cysticerci recovered from clinically and radiologically heterogeneous patients with neurocysticercosis
}

\author{
Héctor Palafox-Fonseca1, Gerardo Zúñiga ${ }^{2}$, Raúl José Bobes¹, Tzipe Govezensky', \\ Daniel Piñero ${ }^{3}$, Laura Texco-Martínez ${ }^{1}$, Agnès Fleury, ${ }^{1,4}$, Jefferson Proaño ${ }^{5}$, \\ Graciela Cárdenas ${ }^{6}$, Marisela Hernández' ${ }^{1}$ Edda Sciutto ${ }^{1}$, Gladis Fragoso ${ }^{1 /+}$
}

\footnotetext{
${ }^{1}$ Instituto de Investigaciones Biomédicas ${ }^{3}$ Instituto de Ecología, Universidad Nacional Autónoma de México, México DF, México

${ }^{2}$ Escuela Nacional de Ciencias Biológicas, Instituto Politécnico Nacional, México DF, México ${ }^{4} U n i d a d$ Periférica del

Instituto de Investigaciones Biomédicas, México DF, México ${ }^{5}$ Hospital de Especialidades Centro Médico Nacional Siglo XXI,

Instituto Mexicano del Seguro Social, México DF, México ${ }^{6}$ Instituto Nacional de Neurología y Neurocirugía, México DF, México
}

\begin{abstract}
Neurocysticercosis (NC) is a clinically and radiologically heterogeneous parasitic disease caused by the establishment of larval Taenia solium in the human central nervous system. Host and/or parasite variations may be related to this observed heterogeneity. Genetic differences between pig and human-derived T. solium cysticerci have been reported previously. In this study, 28 cysticerci were surgically removed from 12 human NC patients, the mitochondrial gene that encodes cytochrome $b$ was amplified from the cysticerci and genetic variations that may be related to NC heterogeneity were characterised. Nine different haplotypes $(\mathrm{Ht})$, which were clustered in four haplogroups (Hg), were identified. $\mathrm{Hg} 3$ and 4 exhibited a tendency to associate with age and gender, respectively. However, no significant associations were found between NC heterogeneity and the different $\mathrm{T}$. solium cysticerci Ht or Hg. Parasite variants obtained from patients with similar NC clinical or radiological features were genetically closer than those found in groups of patients with a different NC profile when using the Mantel test. Overall, this study establishes the presence of genetic differences in the Cytb gene of T. solium isolated from human cysticerci and suggests that parasite variation could contribute to NC heterogeneity.
\end{abstract}

Key words: neurocysticercosis - Taenia solium - cysticercosis - genetic variability

Taenia solium neurocysticercosis (NC) is a parasitic disease that seriously threatens human health in developing countries (Rodriguez-Canul et al. 1999, Sciutto et al. 2000). This disease is also present in Mexico (Fleury et al. 2010) and Mexico's close proximity to the United States of America (USA) is thought to be one of the main causes of a recent NC emergence in the USA due to worker immigration (Sorvillo et al. 2011).

$\mathrm{NC}$ exhibits a heterogeneous clinical manifestation that ranges from asymptomatic cases to severe neurological symptoms (Fleury et al. 2004, 2011, Sotelo 2011). Current evidence indicates that patient genetic background and immune status contribute to the clinical course and outcome of the disease (Del Brutto et al. 1988, Fleury et al. 2004, 2010, Chavarría et al. 2005, Sáenz et al. 2006, Cárdenas et al. 2012). In addition, age and gender have previously been shown to correlate with

doi: 10.1590/0074-0276130308

Financial support: Dirección General de Apoyo Académico/UNAM (IN226707), SAGARPA: Convenio SENASICA-UNAM 29419-14992-VIII-II

HP-F was funded with a scholarship from CONACyT (6622).

+ Corresponding author: gladis@unam.mx

Received 7 June 2013

Accepted 16 August 2013 clinical differences; some studies have shown a lower prevalence of symptomatic NC in children than in adults and females exhibit a stronger inflammatory response to T. solium infection than males do (Fleury et al. 2004, 2011, Chavarria et al. 2005). Less attention has focused on the relevance of parasite variations on NC severity. Studies performed in $T$. solium cysticerci recovered from pigs with different geographical origins have shown that genetic variations of the parasite may be involved in pathogenicity (Maravilla et al. 2003, 2008, Vega et al. 2003, Hinojosa-Juarez et al. 2008, Bobes et al. 2010). Moreover, genetic differences in the mitochondrial coxl and ribosomal ITS1 genes were observed in 13 cysticerci obtained from NC patients; however, this study did not attempt to correlate parasite variation and $\mathrm{NC}$ severity (Hinojosa-Juarez et al. 2008).

As no previous study has tested the correlations between polymorphisms in any specific parasite gene and clinical differences among NC patients, the focus of this study was to search for an association between these two factors. The $C y t b$ gene is a mitochondrial gene that is highly conserved among species (Hey 1997, Simmons \& Weller 2001). In this study, Cytb was selected as a molecular marker because polymorphisms in this gene may reflect variations in other genes, some of which could directly participate in disease outcome (Laclette et al. 1992). In addition, Cytb was recently used in the phylogenetic analysis of taenids and was one of the genes whose analysis first indicated that $T$. solium may have di- 
verged into two strains. One of these strains was isolated from Asia and the other strain was isolated from Africa and Latin America (Okamoto et al. 2001). The possible reasons for this divergence have been recently explored (Michelet \& Dauga 2012). Cytb has also been employed for molecular epidemiological surveys of other parasitic diseases (Sakuma et al. 2012) and in the clinical diagnosis of cysticercosis (Kobayashi et al. 2013).

Thus, an analysis of the $C y t b$ gene sequences isolated from different clinical patients with $\mathrm{NC}$ was conducted.

\section{SUBJECTS, MATERIALS AND METHODS}

Samples - Twenty-eight T. solium cysticerci were obtained from 12 patients who underwent surgical cysticercus removal after being diagnosed with $\mathrm{NC}$ based on clinical assessment and radiologic imaging. Twenty-two cysticerci were excised from patients at the National Institute of Neurology and Neurosurgery Manuel Velasco Suárez, Secretary of Health, Mexico City, and six cysticerci were excised from patients at the National Medical Center Siglo XXI (Hospital Specialties Dr Bernardo Sepúlveda G, Research Unit of Neurological Diseases), Mexico City. Cyst samples were donated by both hospital centres and the DNA was extracted from each sample. The patient demographic data, the number and location of the recovered parasites and the patient inflammatory status are described in Table I. Immediately after the surgical procedure, the parasites were exhaustively washed with phosphate buffered saline, dried and frozen at $-70^{\circ} \mathrm{C}$ until DNA extraction.

Clinical features - The clinical files of $12 \mathrm{NC}$ patients were retrieved to collect demographic data (age and gender), clinical and histological findings (intracranial hypertension and inflammation level, respectively), characteristics of cerebrospinal fluid (cell count and protein level) and radiological features (location, number and status of parasites, arachnoiditis, ependymitis and hydrocephalus) (Table I).

Genomic DNA (gDNA) extraction - gDNA from $T$. solium cysticerci excised from infected human patients was purified using the DNeasy Blood and Tissue kit (Qiagen, Hilden, Germany) according to the manufacturer's recommended protocol for DNA isolation from animal tissue.

Polymerase chain reaction (PCR) amplification and DNA sequencing - The complete 1,068-bp Cytb gene was amplified using the primer set described by Nakao et al. (2002) (Cytb/F forward 5'-ATAAACTGATAGATTGTGGTTC-3' and $C y t b / \mathrm{R}$ reverse 5'-CATATGACTGTCTAATGAAGAAAA-3'). All PCR reactions were performed in a final volume of $50 \mu \mathrm{L}$ containing $10 \mu \mathrm{L}$ of 5X Phusion HF buffer (Finnzymes), $1 \mu \mathrm{L}$ of $100 \mathrm{mM}$ deoxyribonucleoside triphosphates (Invitrogen), $1 \mu \mathrm{L}$ of the corresponding forward and reverse primers at a concentration of $20 \mathrm{ng} / \mu \mathrm{L}$ and $0.5 \mu \mathrm{L}$ of Phusion DNA polymerase (Finnzymes). gDNA (500 ng) was added to each reaction. Briefly, the PCR conditions were as follows: initial denaturation at $72^{\circ} \mathrm{C}$ for $30 \mathrm{~s}$, followed by 30 denaturation cycles at $72^{\circ} \mathrm{C}$ for $10 \mathrm{~s}$, annealing at $58^{\circ} \mathrm{C}$ for $30 \mathrm{~s}$, extension at $72^{\circ} \mathrm{C}$ for $1 \mathrm{~min}$ and a final cycle at $72^{\circ} \mathrm{C}$ for $5 \mathrm{~min}$ on a Corbett Research thermal cycler CG1-96 (Corbett Life Sciences, San Francisco, USA). Amplification products were harvested and purified using the QIAquick PCR purification kit (Qiagen) according to the manufacturer's instructions. All sequencing reactions were performed in a Big Dye Terminator v. 3.1 cycle sequencing kit (Applied Biosystems, Life Technologies, Carlsbad, California, USA) and sequenced using a 3130XL Sequencer (Applied Biosystems).

Sequence analysis - The 28 sequences were assembled manually, edited in BioEdit v. 7.09 (Hall 1999) and aligned with CLUSTALX v. 2.0.12 (Thompson et al. 1997). A maximum-likelihood phylogenetic inference analysis of the 28 sequences was performed with approximate likelihood ratio test Maximum-Likelihood Phylogenies (atgc.lirmm.fr/phyml/) (Guindon \& Gascuel 2003) using the F81 model (Felsenstein 1981) and the data were analysed with ModelTest software (Posada \& Crandall 2001). This model was the most appropriate for our sequence set according to the Bayesian Information Criterion (BIC) implemented in ModelTest v. 3.7 (Posada \& Crandall 2001) $(\mathrm{BIC}=3288.625$, $-\ln \mathrm{L}$ $=1445.567$; nucleotide base frequency: FreqA $=0.231$, FreqC $=0.091$, FreqG $=0.215$, FreqT $=0.461$ ). The results were confirmed with Network 4.6.1.0 (fluxus-engineering.com) (Polzin \& Daneschmand 2003) using the median-joining method (Bandelt et al. 1999) with the default parameters of this software.

Haplotypes (Ht) (a statistically defined set of singlenucleotide polymorphisms in a specific gene) present in our sequence sets were defined directly from the alignment. In addition, we defined haplogroups ( $\mathrm{Hg}$ ) (a collection of potential $\mathrm{Ht}$ that belong to same group or clade) based on the clustering of 28 sequences into a tree and network. The $\mathrm{Ht}$ and $\mathrm{Hg}$ were tested for associations with patient clinical manifestations.

Statistical analysis - To evaluate a possible association between 11 clinical manifestations in each patient (Table I) and cyst genetic variation, we used two methods: (i) the relationship between the matrices of parasite pairwise genetic distance and the NC patients' pairwise phenotypic distance using the Mantel test and (ii) the association of different $\mathrm{Ht}$ and $\mathrm{Hg}$ with clinical manifestations in NC patients (Table I) using Fisher's exact test.

For the first method, genetic distances among cysticerci were estimated using the F81 nucleotide substitution model (Felsenstein 1981). As the phenotypic data were coded as binary data $(1,0)$ (Table II), a phenotypic distance among NC patients was estimated using the relation 1-single matching index (Romesburg 1990). Finally, F81 and phenotypic distance matrices were compared using the non-parametric Mantel test (Mantel 1967) after 10,000 permutations with NTSYSpc v 2.02j (Rohlf 1997).

For the second method, $\mathrm{Hg}$ were coded as binary data to compare one $\mathrm{Hg}$ to the remaining three $\mathrm{Hg}$ in $2 \times 2$ contingency tables. Likewise patients, classified as those with a single cyst vs. those with multiple cysts and patients harbouring cysts with a single sequence $\mathrm{Ht}$ at the 


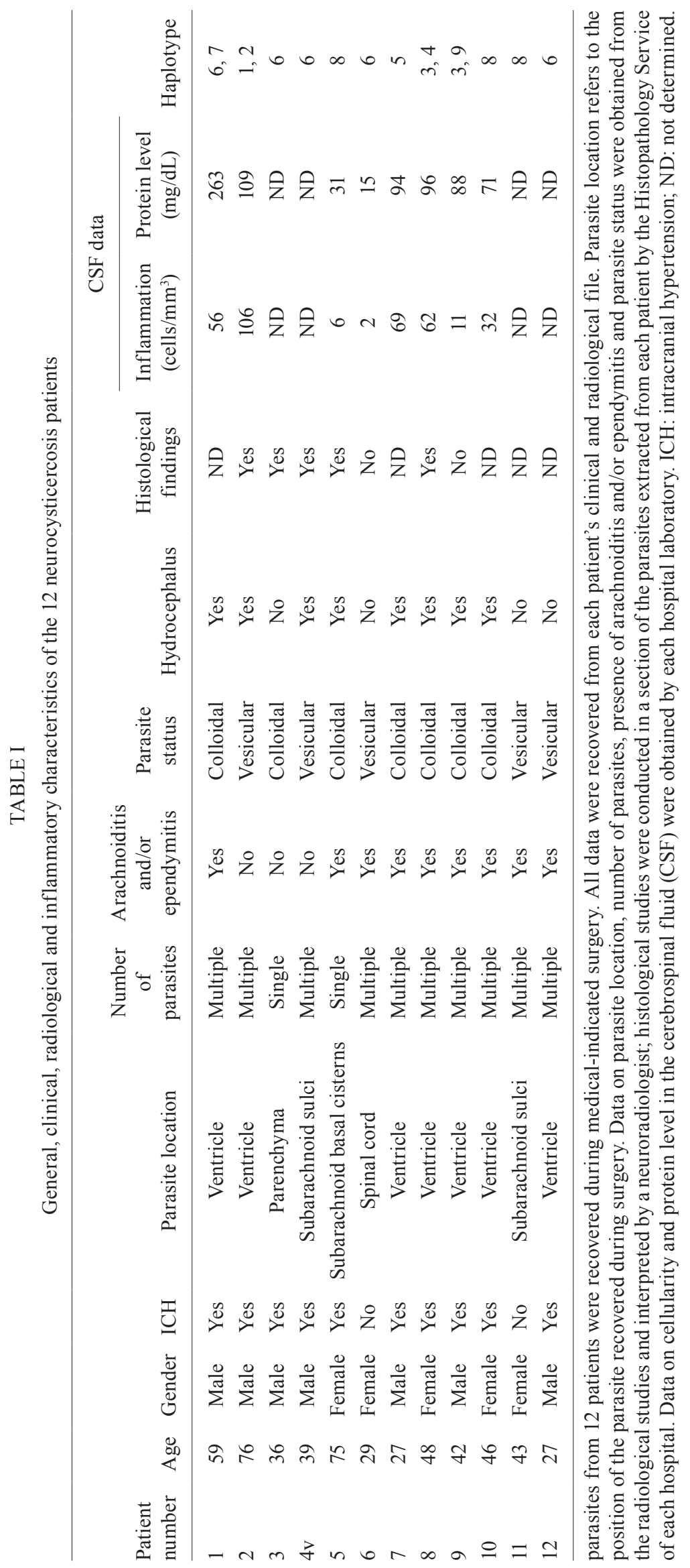


studied locus vs. those with more than one sequence $\mathrm{Ht}$ were tested for association with general, clinical and radiological features using the same statistical test. Results were considered statistically significant at a $p$ value $<0.1$.

Ethics - Cysticerci were removed during neurosurgery. Surgery was indicated by the neurologist based on the clinical condition of the patient and the feasibility of the procedure. Cysticerci samples were kindly donated by the hospital centres for genetic variation studies and all samples were anonymous. According to hospital policy, patients were required to sign informed consent forms for the surgical procedure. This study conformed to all research regulations regarding the use of human subjects as required by Mexican law and international regulations and the study adhered to the ethical guidelines in the General Rules of Health from Clinical Investigation. The research protocol was approved by the Ethical Committee of XXI Century National Medical Center, Mexican Social Security Institute.

\section{RESULTS}

Sequencing results of the Cytb gene from all tested cysticerci suggested that all cysticerci were of the American/African genotype (Nakao et al. 2002). The Cytb gene sequences from 28 cysticerci from 12 patients were analysed; only one insertion/deletion (nucleotide 761) was detected in the first amplicon obtained from parasite 5 , which was excised from patient 2 . In addition, 13 polymorphic sites were found, $61.53 \%$ of which were informative sites (Fig. 1).

Significant statistical associations were observed between the F81 genetic distance and 11 host variables $\left(r_{\text {Mantel }}\right.$ $=0.327, \mathrm{p}=0.0001)$. Furthermore, nine Ht (accesses
JQ973073 H2, JQ973074 H5, JQ973075 H3, JQ973076 H4, JQ973077H6, JQ973078 H7, JQ973079 H8 and JQ973080 H9) were identified among all 28 sequences (Fig. 1), which were subsequently clustered into four $\mathrm{Hg}$ in the tree topology (bootstrap values $\geq 80 \%$ ) (Fig. 2).

The first $\mathrm{Hg}$ was comprised of seven parasites, which were all excised from the same patient and contained polymorphisms at nucleotides 340,360 and 651 [guanine $(\mathrm{G})$ was replaced by cytosine (C), adenine (A) by $\mathrm{G}$ and $\mathrm{C}$ by thymine $(\mathrm{T})$, respectively]. The parasite with a deletion at nucleotide 761 was included in this group. The second $\mathrm{Hg}$ included six cysticerci from three different patients. These sequences were grouped based on the variant at nucleotide 340 ( $\mathrm{G}$ by C); however, three of them exhibited mutations at other positions (Fig. 1). The third $\mathrm{Hg}$ included 10 parasites from five patients with variations at positions 543 (G by A) and 546 (A by G). The fourth $\mathrm{Hg}$ was comprised of five parasites from three patients who exhibited variations at nucleotides 672 and 914 (C by $\mathrm{G}$ and $\mathrm{A}$ by $\mathrm{G}$, respectively) (Figs 1, 2).

A tendency towards association between $\mathrm{Hg} 3$ and age was observed $(p=0.07)$ : of the five patients harbouring parasites of $\mathrm{Hg} \mathrm{3}$, four were younger than 40, whereas six of the seven patients exhibiting cysts from other $\mathrm{Hg}$ were older than 40 . The three patients with parasites from $\mathrm{Hg} 4$ were female. In contrast, only two out of seven patients infected with parasites from other $\mathrm{Ht}$ groups were female $(p=0.04)$. Younger patients tended to harbour parasites with the same $\mathrm{Ht}$, whereas the four patients presenting with cysticerci containing two $\mathrm{Ht}$ were older than $40(p=0.07)$. No statistically significant association between $\mathrm{Hg}$ and clinical or radiological manifestations was observed.

TABLE II

General, clinical and radiological features of neurocysticercosis patients used in the association analysis and binary transformation

\begin{tabular}{lcc}
\hline Category & Patient features & Binary transformation \\
\hline 1 & Age & $>40(1),<40(0)$ \\
2 & Gender & Female (1), male (0) \\
3 & Clinical severity & Yes (1), no (0) \\
4 & (intracranial hypertension symptoms) & \\
5 & Parasite location & SAb or Sc or Iv (1), SAs or P (0) \\
6 & Number of parasites & Multiple (1), single (0) \\
7 & Arachnoiditis and ependymitis & Yes (1), no (0) \\
8 & Parasite status & Colloidal (1), vesicular $(0)$ \\
9 & Hydrocephalus & Yes (1), no (0) \\
10 & Histological findings & Presence of inflammation (1) ${ }^{a}$, \\
11 & Cerebral spinal fluid F cell count & absence of inflammation $(0)$
\end{tabular}

$a$ : for histological findings, inflammation was defined as the presence of lymphocytes and macrophages; Iv: intraventricular; P: paremchyma; SAb: subarachnoid basal cisterns; SAs: subarachnoid of sulci; Sc: spinal cord. 


\begin{tabular}{|c|c|c|c|c|c|c|c|c|c|c|c|c|c|c|c|c|}
\hline \multirow{2}{*}{$\begin{array}{l}\text { Patient } \\
\text { number }\end{array}$} & \multirow[t]{2}{*}{ Cysticercinumber } & \multicolumn{13}{|c|}{ Nucleotide position } & \multirow[b]{2}{*}{ Haplotype } & \multirow[b]{2}{*}{ Haplogroup } \\
\hline & & 273 & 292 & 294 & 340 & 360 & 508 & 543 & 546 & 585 & 651 & 672 & 914 & 1053 & & \\
\hline \multirow{7}{*}{2} & 5 & $*$ & $*$ & $\star$ & $C$ & $G$ & * & * & * & * & $T$ & * & $*$ & $*$ & 1 & \multirow{7}{*}{1} \\
\hline & 7 & $\dddot{\cdots}$ & $\dddot{\cdots}$ & $\dddot{*}^{\cdots}$ & $\dddot{c}$ & $G$ & $\because \cdots$ & $\dddot{\dddot{\varkappa}}$ & $\dddot{*}$ & $\dddot{x}^{\cdots}$ & $\dddot{T}$ & $\cdots^{\cdots}$ & 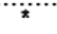 & $\dddot{*}$ & & \\
\hline & 6 & $\star$ & * & * & $c$ & G & * & * & * & * & $T$ & * & * & * & & \\
\hline & 1 & * & * & * & $c$ & G & * & * & * & * & $T$ & * & * & * & & \\
\hline & 4 & * & $\star$ & * & $c$ & $G$ & * & * & * & * & $T$ & * & * & * & 2 & \\
\hline & 3 & $*$ & * & * & $c$ & G & $*$ & * & * & * & $T$ & * & * & * & & \\
\hline & 2 & * & $\star$ & * & $c$ & G & * & * & * & * & $T$ & * & * & * & & \\
\hline \multirow[t]{2}{*}{9} & 1 & $\cdots$ & $\dddot{*}$ & $\cdots$ & $\dddot{c}$ & $" \cdots$ & $\because \cdots$ & 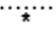 & $\because *$ & $\dddot{*}$ & $\dddot{*}$ & $\dddot{\star}$ & $\approx$ & 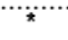 & & \multirow{6}{*}{2} \\
\hline & 2 & * & * & * & $c$ & * & * & * & * & * & * & * & * & * & 3 & \\
\hline \multirow[t]{2}{*}{8} & 1 & * & * & * & c & * & * & * & * & * & * & * & * & * & & \\
\hline & 2 & $\cdots$ & $\because$ & $\cdots$ & $\dddot{c}$ & 西 & $\dddot{*}$ & 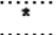 & $\dddot{\cdots}$ & $G$ & 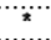 & $\dddot{~} \dddot{2}$ & $\approx$ & $\dddot{*}$ & 4 & \\
\hline 7 & 1 & 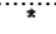 & $\dddot{*}$ & 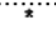 & $\dddot{c}$ & 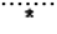 & $T$ & $\dddot{*}$ & $\dddot{*}$ & ${ }^{\prime \cdots}$ & $\dddot{*}$ & $\dddot{\dddot{*}}$ & $\dddot{*}$ & G & 5 & \\
\hline 9 & 3 & $c$ & $G$ & $\dddot{A}$ & $c$ & 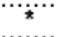 & 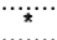 & $\dddot{*}$ & $\dddot{*}$ & 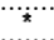 & 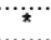 & $\dddot{\sharp}$ & $\pi$ & $\dddot{~} \dddot{*}$ & 9 & \\
\hline \multirow[t]{2}{*}{4} & 1 & $\dddot{*}$ & $\dddot{*} \cdots$ & $\dddot{*}$ & 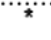 & $\dddot{*}$ & $\dddot{*}$ & A & $G$ & $\dddot{*}$ & $\dddot{*} \cdots$ & $\dddot{\sharp}$ & 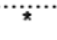 & $\dddot{*}$ & & \multirow{10}{*}{3} \\
\hline & 2 & * & * & * & * & * & * & $A$ & $G$ & * & * & * & * & * & & \\
\hline \multirow[t]{2}{*}{6} & 2 & * & * & * & $\approx$ & * & * & $A$ & $G$ & * & * & * & * & * & & \\
\hline & 3 & * & * & * & * & * & * & $A$ & $G$ & * & * & * & * & * & & \\
\hline \multirow[t]{2}{*}{12} & 1 & * & * & * & * & * & * & $A$ & $G$ & * & * & * & * & * & 6 & \\
\hline & 2 & $\star$ & * & * & * & * & $\star$ & $A$ & $G$ & * & * & * & * & * & & \\
\hline 1 & 2 & * & * & * & * & * & $\star$ & $A$ & $G$ & * & * & * & * & * & & \\
\hline 6 & 1 & 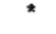 & * & * & * & * & $*$ & $A$ & $G$ & * & * & * & * & * & & \\
\hline 3 & 1 & ${ }^{*}$ & ${ }_{\text {. }}^{\star}$ & ${ }^{*}$ & ${ }_{\ldots}^{*}$ & * & * & $A$ & $G$ & ${ }^{*}$ & $\star *$ & ${ }^{*}$ & * & ${ }^{*}$ & & \\
\hline \multirow[t]{2}{*}{1} & 1 & $\star$ & $G$ & 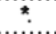 & $\approx$ & $\star$ & $\star$ & $A$ & $G$ & $\approx$ & $*$ & $\star$ & $\star$ & $\star$ & 7 & \\
\hline & 2 & $x$ & $\approx$ & $x$ & $\approx$ & $\approx$ & $\approx$ & $\approx$ & 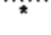 & $\approx$ & $\approx$ & $G$ & $G$ & $\approx$ & & \\
\hline \multirow[t]{2}{*}{11} & 3 & $\approx$ & $\star$ & * & $\approx$ & * & $\approx$ & * & * & * & * & $G$ & $G$ & * & & \\
\hline & 1 & * & $\star$ & * & * & * & * & * & * & * & * & $G$ & $G$ & * & 8 & 4 \\
\hline 10 & 1 & * & * & * & * & * & * & * & * & * & * & G & $G$ & $\star$ & & \\
\hline 5 & 1 & * & $\star$ & $\star$ & * & * & $\star$ & * & * & * & * & $G$ & $G$ & * & & \\
\hline
\end{tabular}

Fig. 1: polymorphic sites in Cytb gene sequences of 28 parasites from 12 neurocysticercosis patients. The position and nucleotide changes found haplotypes and haplogroups formed by different haplotypes are shown.

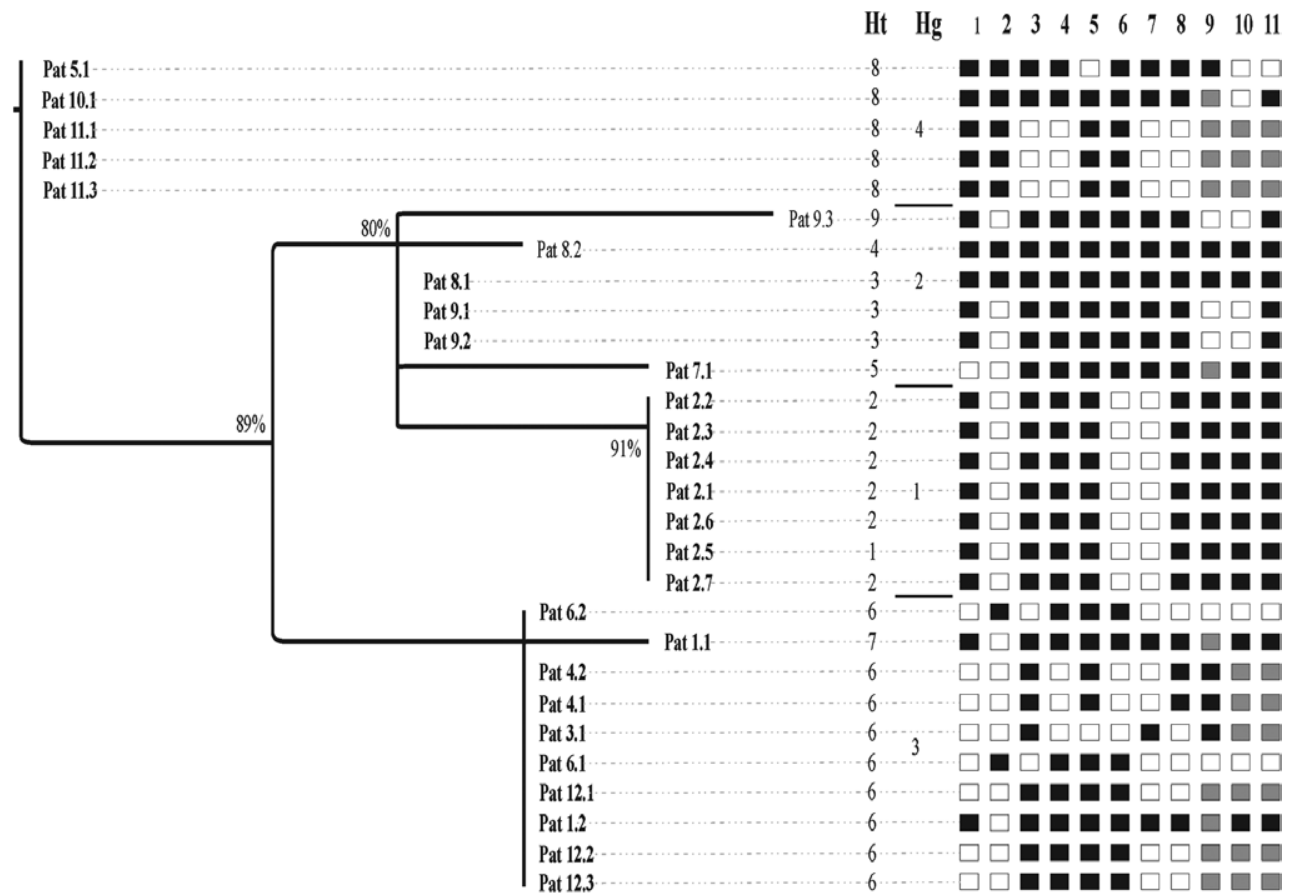

$6.0 \overline{\mathrm{E}-4}$ Substitution/site

Fig. 2: maximum-likelihood phylogenetic tree based on single nucleotide polymorphism (SNP) differences across the Cytb gene of Taenia solium cysticerci. A maximum-likelihood phylogenetic tree of the 28 T. solium cysticerci from 12 patients based on SNP differences across the 1,068 bp of the complete Cytb gene (left) is shown. Haplotypes (Ht), haplogroups ( $\mathrm{Hg}$ ), as well as demographic, clinical, radiological and inflammatory features of each patient-derived cyst are shown (right). The number of each column corresponds to the same clinical category shown in Table II. White and dark squares correspond to the binary transformation according to Table II. 


\section{DISCUSSION}

In this study, the sequences of the mitochondrial $C y t b$ gene were studied in 28 cysticerci surgically excised from NC patients. The genetic variations observed were clustered into nine $\mathrm{Ht}$ and four $\mathrm{Hg}$. This finding highlights the genetic heterogeneity among cysticerci isolated from human patients. These genetic variations are consistent with the genetic heterogeneity observed among swine-derived T. solium metacestodes isolated from different areas of Mexico and other endemic countries (Maravilla et al. 2003, 2008, Vega et al. 2003, Bobes et al. 2010, Barcelos et al. 2012).

A significant association between the 11 included host features and the genetic distances among parasites was observed (Mantel test). This result indicates that patients with similar features harbour parasites that are more closely related, which suggests that parasite diversity may contribute to the heterogeneous clinical manifestations observed in NC patients (Fleury et al. 2010). Clinical and radiological heterogeneity is a main characteristic of NC. Although previous studies have shown that host genetic background, sex, age and immune status affect the susceptibility to infection and disease (Del Brutto et al. 1988, Chavarria et al. 2005, Sáenz et al. 2006), this is the first study suggesting that parasite heterogeneity may contribute to disease heterogeneity. It is important to note that the observed genetic variation in the mitochondrial $C y t b$ gene among the parasites and the association of genetic variation with the observed clinical features could be due to the action of $C y t b$ (i.e., $C y t b$ encodes a protein that plays an important role in electron transfer, the respiratory chain and oxidative phosphorylation in aerobic organisms) (Fernández et al. 2008, Chen et al. 2009). However, it is possible that this association may reflect an indirect effect of $C y t b$ genetic variation due to variation in other genes, which could directly affect disease outcome (Laclette et al. 1992).

The selection of the Cytb gene for this molecular study of $T$. solium merits some discussion. First, T. solium mitochondrial genes, such as col, Cytb and nad, are more polymorphic than nuclear genes and are more informative for molecular epidemiology purposes (Martínez-Hernández et al. 2009). Cytb was also an attractive target for this study because a study of the col gene was not feasible: the complete amplification of the col gene from human brain cysticerci collected in this study was not possible (data not shown) for reasons that are not yet understood.

In addition, we observed a tendency of association between $\mathrm{Hg} 3$ and 4 with age and gender, respectively. Considering the relevance of gender and age in NC pathogenesis, these tendencies also merit some discussion. It is known that the neuroinflammation accompanying severe $\mathrm{NC}$ forms is more intense in women. In addition, the encephalitic form of NC, which is caused by multiple degenerating parasites located in the parenchyma, is an inflammatory form of the disease that is found almost exclusively in female patients (Fleury et al. 2010). With respect to age, most paediatric patients present a benign form of the disease with parasites localised in the parenchyma; however, adult patients present with an extra-parenchymal form and more severe forms of the disease (Sáenz et al. 2006). Thus, the underlying cause of some of these differences may involve parasite genetic variation.

No other associations among the individual radiological or clinical variables of $\mathrm{NC}$ patients and $C y t b \mathrm{Ht}$ or $\mathrm{Hg}$ were observed. These negative results should be interpreted with caution because of our small sample size, which could influence these results.

The influence of genetic variation in infectious organisms on the clinical course of the resulting disease has been described previously ( $\mathrm{Li}$ et al. 2010). In the case of $T$. solium cysticercosis, genetic variation of the parasite has reportedly been associated with different parasite antibody recognition patterns (Barcelos et al. 2012).

In conclusion, our results suggest that a parasite genetic profile may contribute to NC heterogeneity; however, no individual associations with clinical or radiological characteristics were found.

\section{ACKNOWLEDGEMENTS}

To MC Jorge Yañez and MC Patricia de la Torre, for DNA sequencing, to Karel Estrada, for providing the Cytb gene sequence from the T. solium genome database, to Dr Rosalba Vega Orozco, for the histological analysis of the samples, to Juan Francisco Rodriguez, for copy-editing the English version, to the neurosurgical team of INNN, to Barbara Nettel, of the National Medical Center Siglo XXI, IMSS and to Doctorado en Ciencias Biomédicas, UNAM.

\section{REFERENCES}

Bandelt H, Forster P, Röhl AA 1999. Median-joining network for inferring intraspecific phylogenies. Mol Biol Evol 16: 37-48.

Barcelos IS, Souza MA, Pena JDO, Machado GA, de Moura LGM, Costa-Cruz JM 2012. Genetic polymorphism in Taenia solium metacestodes from different Brazilian geographic areas. Mem Inst Oswaldo Cruz 107: 24-30.

Bobes RJ, Fragoso G, Reyes-Montes M del R, Duarte-Escalante E, Vega R, Aluja AS, Zúñiga G, Morales J, Larralde C, Sciutto E 2010. Genetic diversity of Taenia solium cysticerci from naturally infected pigs of central Mexico. Vet Parasitol 168: 130-135.

Cárdenas G, Valdez R, Sáenz B, Bottasso O, Fragoso G, Sciutto E, Romano MC, Fleury A 2012. Impact of Taenia solium neurocysticercosis upon endocrine status and its relation with immuno-inflammatory parameters. Int J Parasitol 42: 171-176.

Chavarría A, Fleury A, García E, Márquez C, Fragoso G, Sciutto E 2005. Relationship between the clinical heterogeneity of neurocysticercosis and the immune-inflammatory profiles. Clin Immunol 116: 271-278.

Chen J, Sun Y, Manglai D, Min L, Pan Q 2009. The association analysis between $C y t b$ polymorphism and growth traits in three Chinese donkey breeds. Livestock Prod Sci 126: 306-309.

Del Brutto OH, García E, Talámas O, Sotelo J 1988. Sex-related severity of inflammation in parenchymal brain cysticercosis. Arch Intern Med 148: 544-546.

Felsenstein J 1981. Evolutionary trees from DNA sequences: a maximum likelihood approach. J Mol Evol 17: 368-376.

Fernández AI, Alves E, Fernández A, de Pedro E, López-García MA, Ovilo C, Rodríguez MC, Silió L 2008. Mitochondrial genome 
polymorphisms associated with longissimus muscle composition in Iberian pigs. J Anim Sci 86: 1283-1290.

Fleury A, Carrillo-Mezo R, Flisser A, Sciutto E, Corona T 2011. Subarachnoid basal neurocysticercosis: a focus on the most severe form of the disease. Expert Rev Anti Infect Ther 9: 123-133.

Fleury A, Dessein A, Preux PM, Dumas M, Tapia G, Larralde C, Sciutto E 2004. Symptomatic human neurocysticercosis-age, sex and exposure factors relating with disease heterogeneity. $\mathrm{J} \mathrm{Neu-}$ rol 251: 830-837.

Fleury A, Escobar A, Fragoso G, Sciutto E, Larralde C 2010. Clinical heterogeneity of human neurocysticercosis results from complex interactions among parasite, host and environmental factors. Trans R Soc Trop Med Hyg 104: 243-250.

Guindon S, Gascuel O 2003. Simple, fast and accurate algorithm to estimate large phylogenies by maximum likelihood. Syst Biol 52: 696-704.

Hall TA 1999. BioEdit: a user-friendly biological sequence alignment editor and analysis program for Windows 95/98/NT. Nucl Acids Symp Ser 41: 95-98.

Hey J 1997. Mitochondrial and nuclear genes present conflicting portraits of human origins. Mol Biol Evol 14: 166-172.

Hinojosa-Juarez AC, Sandoval-Balanzario M, McManus DP, Monroy-Ostria A 2008. Genetic similarity between cysticerci of Taenia solium isolated from human brain and from pigs. Infect Genet Evol 8: 653-656.

Kobayashi K, Nakamura-Uchiyama F, Nishiguchi T, Isoda K, Kokubo Y, Ando K, Katurahara M, Sako Y, Yanagida T, Ito A, Iwabuchi S, Ohnishi K 2013. Rare case of disseminated cysticercosis and taeniasis in a Japanese traveller after returning from India. Am $J$ Trop Med Hyg 89: 58-62.

Laclette JP, Shoemaker CB, Richter D, Arcos L, Pante N, Cohen C, Bing D, Nicholson-Weller A 1992. Paramyosin inhibits complement C1. J Immunol 1481: 124-128.

Li H, Sullivan DG, Feuerborn N, McArdle S, Bekele K, Pal S, Yeh M, Carithers RL, Perkins JD, Gretch DR 2010. Genetic diversity of hepatitis $\mathrm{C}$ virus predicts recurrent disease after liver transplantation. Virology 402: 248-255.

Mantel N 1967. The detection of disease clustering and a generalized regression approach. Cancer Res 27: 209-220.

Maravilla P, Gonzalez-Guzman R, Zuñiga G, Peniche A, DominguezAlpizar JL, Reyes-Montes R, Flisser A 2008. Genetic polymorphism in Taenia solium cysticerci recovered from experimental infections in pigs. Infect Genet Evol 8: 213-216.

Maravilla P, Souza V, Valera A, Romero-Valdovinos M, Lopez-Vidal Y, Dominguez-Alpizar JL, Ambrosio J, Kawa S, Flisser A 2003. Detection of genetic variation in Taenia solium. J Parasitol 89: 1250-1254.

Martínez-Hernández F, Jimenez-Gonzalez DE, Chenillo P, AlonsoFernandez C, Maravilla P, Flisser A 2009. Geographical widespread of two lineages of Taenia solium due to human migrations: can population genetic analysis strengthen this hypothesis? Infect Genet Evol 9: 1108-1114.
Michelet L, Dauga C 2012. Molecular evidence of host influences on the evolution and spread of human tapeworms. Biol Rev Camb Philos Soc 87: 731-741.

Nakao M, Okamoto M, Sako Y, Yamasaki H, Nakaya K, Ito A 2002. A phylogenetic hypothesis for the distribution of two genotypes of the pig tapeworm Taenia solium worldwide. Parasitology 124: 657-662.

Okamoto M, Nakao M, Sako Y, Ito A 2001. Molecular variation of Taenia solium in the world. Southeast Asian J Trop Med Public Health 2 (Suppl.): 90-93.

Polzin T, Daneschmand SV 2003. On Steiner trees and minimum spanning trees in hypergraphs. Oper Res Lett 31: 12-20.

Posada D, Crandall KA 2001. Selecting the best fit model of nucleotide substitution. Syst Biol 50: 580-601.

Rodriguez-Canul R, Fraser A, Allan JC, Dominguez-Alpizar JL, Argaez-Rodriguez F, Craig PS 1999. Epidemiological study of Taenia solium taeniasis/cysticercosis in a rural village in Yucatan State, Mexico. Ann Trop Med Parasitol 93: 57-67.

Rohlf FJ 1997. NTSYS-pc: Numerical Taxonomy and Multivariate Analysis System version 2.01. Available from: exetersoftware. com/downloads/ntsysguide21.pdf.

Romesburg CH 1990. Cluster analysis for researchers, Malabar Florida Krieger Co, Florida, 334 pp.

Sáenz B, Ruíz-Garcia M, Jiménez E, Hernández-Aguilar J, Suastegui R, Larralde C, Sciutto E, Fleury A 2006. Neurocysticercosis: clinical, radiologic and inflammatory differences between children and adults. Pediatr Infect Dis J 9: 801-803.

Sakuma M, Fukuda K, Takayama K, Kobayashi Y, Shimokawa Miyama T, Setoguchi A, Endo Y 2012. Molecular epidemiological survey of the Babesia gibsoni cytochrome $b$ gene in western Japan. J Vet Med Sci 74: 1341-1344.

Sciutto E, Fragoso G, Fleury A, Laclette JP, Sotelo J, Aluja A, Vargas L, Larralde C 2000. Taenia solium disease in humans and pigs: an ancient parasitosis disease rooted in developing countries and emerging as a major health problem of global dimensions. Microbes Infect 2: 1875-1890.

Simmons RB, Weller SJ 2001. Utility and evolution of cytochrome $b$ in insects. Mol Phylogenet Evol 20: 196-210.

Sorvillo F, Wilkins P, Shafir S, Eberhard M 2011. Public health implications of cysticercosis acquired in the United States. Emerg Infec Dis 17: 1-6.

Sotelo J 2011. Clinical manifestations, diagnosis and treatment of neurocysticercosis. Curr Neurol Neurosci Rep 11: 529-535.

Thompson JD, Gibson TJ, Plewniak F, Jeanmougin F, Higgins DG 1997. The CLUSTALX windows interface: flexible strategies for multiple sequence alignment aided by quality analysis tools. Nucleic Acids Res 24: 4876-4882.

Vega R, Piñero D, Ramanankandrasana B, Dumas M, Bouteille B, Fleury A, Sciutto E, Larralde C, Fragoso G 2003. Population genetic structure of Taenia solium from Madagascar and Mexico: implications for clinical profile diversity and immunological technology. Int J Parasitol 33: 1479-1485. 